\title{
Successful cryopreservation of mouse blastocysts using a new vitrification solution
}

\author{
C. A. Valdez ${ }^{1}$, O. Abas Mazni ${ }^{1}$, Y. Takahashi ${ }^{1}$, S. Fujikawa ${ }^{2}$ and \\ H. Kanagawa ${ }^{1}$ \\ ${ }^{1}$ Department of Theriogenology, Faculty of Veterinary Medicine and ${ }^{2}$ Institute of Low Temperature \\ Science, Hokkaido University, Sapporo 060, Japan
}

Summary. Mouse blastocysts were exposed to solutions containing four concentrations $(10,20,30$ and $40 \% \mathrm{v} / \mathrm{v})$ of six permeating cryoprotectants (glycerol, ethylene glycol, propylene glycol, dimethyl sulfoxide, 1,3-butanediol and 2,3-butanediol) in phosphate-buffered saline (PBS) with calf serum (CS) at room temperature $\left(20-22^{\circ} \mathrm{C}\right)$. Blastocysts were exposed to these solutions for various periods, diluted into PBS plus CS with or without $1 \mathrm{~mol}$ trehalose $1^{-1}$ solution and their subsequent survival in vitro was examined. Two-way ANOVA showed a significant interaction $(P<0.01)$ between cryoprotectant type, concentration of cryoprotectant and method of dilution. However, no significant interaction was observed between cryoprotectant type and duration of exposure. Results suggest that cryoprotectant-induced injury to nonfrozen blastocysts is variable and depends on the cryoprotectant used. On the basis of toxicity assays, ethylene glycol was the least harmful and was combined with dimethyl sulfoxide and 1,3-butanediol to produce a new vitrification solution. Mouse blastocysts were successfully cryopreserved using a vitrification solution (designated as VSv) consisting of $20 \%$ ethylene glycol, $20 \%$ dimethyl sulfoxide and 10\% 1,3-butanediol $(\mathrm{v} / \mathrm{v})$. Embryos were equilibrated in two steps, first in an equilibration solution (designated as ESv: $10 \%$ ethylene glycol, $10 \%$ dimethyl sulfoxide and 5\% 1,3-butanediol; v/v) and then to VSv or one-step in VSv at different exposure times at room temperature, and then vitrified by direct plunging into liquid nitrogen. High developmental rates were obtained in vitro when the embryos were exposed to ESv and VSv for 3 and $0.5 \mathrm{~min}$, respectively $(96.2 \%)$ or exposed to VSv for $0.5 \mathrm{~min}(95.4 \%)$. Prolonged exposure time proved detrimental to subsequent embryo development in vitro. When vitrified warmed embryos were transferred immediately to pseudopregnant recipients, the rate of development to normal fetuses did not significantly differ from that of the nonvitrified control (two-step, $54 \cdot 2$ and one-step, $45 \cdot 0$ versus $60.0 \%, P>0.05$ ).

These results suggest that the simple vitrification solution described in this study is effective for the cryopreservation of mouse blastocysts.

Keywords: mouse; blastocyst; vitrification; cryoprotectant; equilibration

\section{Introduction}

The development of vitrification solutions represents a new concept in embryo cryopreservation. Vitrification solutions are aqueous cryoprotectant solutions that do not form ice crystals when cooled at moderate rates to very low temperatures (Fahy et al., 1987), and thus avoid the potentially deleterious effects of intra- and extracellular freezing (Mazur, 1984). However, to achieve good survival after vitrification, embryos must be able to tolerate exposure and dehydration to these highly concentrated solutions (Rall, 1987). 
Preimplantation mouse embryos have been successfully cryopreserved using vitrification solutions with different compositions. The first vitrification solution (VS1; Rall \& Fahy, 1985) was composed of permeating (dimethyl sulfoxide, acetamide and propylene glycol) and nonpermeating (polyethylene glycol) cryoprotectants. This was followed by the development of a simpler solution composed of two permeating (glycerol and propylene glycol) cryoprotectants (Scheffen et al., 1986). Rall (1987) also reported the use of either glycerol or propylene glycol in combination with polyethylene glycol. Kasai et al. (1990) developed a solution composed of a single permeating (ethylene glycol) and two nonpermeating (ficoll and sucrose) cryoprotectants.

However, previous studies (Scheffen et al., 1986; Bielanski, 1987; Valdez et al., 1990b) showed that mouse embryos at different stages differ in their sensitivity when exposed to vitrification solutions. These investigators reported that vitrified warmed mouse blastocysts had very low viability compared with other embryo developmental stages. This paper describes a simple vitrification solution composed of three permeating cryoprotectants that is effective for the cryopreservation of mouse blastocysts.

\section{Materials and Methods}

\section{Source and recovery of embryos}

Female ICR mice, four to seven weeks old and weighing at least $20 \mathrm{~g}$, were used as embryo donors, and eight to twelve week old female mice of the same strain weighing at least $30 \mathrm{~g}$ were used as recipients for embryo transfer.

The mice were superovulated by intraperitoneal injection of $5 \mathrm{iu}$ of pregnant mares' serum gonadotrophin (PMSG) (Teikoku Zoki, Tokyo, Japan), followed by 5 iu of human chorionic gonadotrophin (hCG; Teikoku Zoki) $48 \mathrm{~h}$ later. The females were mated singly with adult males from the same strain and were inspected the following morning for the presence of vaginal plugs (day 1).

Blastocyst-stage embryos were flushed from the excised uteri at 92 to $94 \mathrm{~h}$ after hCG injection using Dulbecco's phosphate-buffered saline (PBS[-]; Nissui Pharmaceutical Co., Tokyo, Japan) in which $0.9 \mathrm{mmol} \mathrm{CaCl} 2.2 \mathrm{H}_{2} \mathrm{O} \mathrm{I}^{-1}$ and $0.49 \mathrm{mmol}$ of $\mathrm{MgCl}_{2} \cdot 6 \mathrm{H}_{2} \mathrm{O} \mathrm{l}^{-1}$ were added (PBS) and supplemented with $10 \%$ heat-inactivated calf serum (CS; Gibco Lab., Life Technologies Inc., NY). After recovery, morphologically normal embryos were washed three times in fresh PBS plus CS, then pooled and held at room temperature $\left(20-22^{\circ} \mathrm{C}\right)$ until used.

\section{Cryoprotectant toxicity assays on nonfrozen blastocysts}

Embryos were pipetted into a plastic culture dish containing $3 \mathrm{ml}$ cryoprotectant, 2,3 -butanediol ( $>98 \%$ mixture of meso-, D- and L-form; 2,3-butandiol, Merck-Schuchardt, Germany), 1,3-butanediol, dimethyl sulfoxide, propylene glycol, ethylene glycol or glycerol (Kanto Chemicals, Tokyo, Japan) in PBS plus CS at room temperature. After exposure, the embryos were pipetted into $3 \mathrm{ml} 1 \mathrm{~mol}$ trehalose $\mathrm{I}^{-1}$ (Sigma, St Louis, MO, USA) in PBS plus CS for 5 min to dilute the cryoprotectant (Valdez et al., 1991). After dilution, embryos were washed three times in PBS plus $\mathrm{CS}$, placed in microdroplets of Whitten's medium (Biggers et al., 1971) and then cultured in vitro at $37^{\circ} \mathrm{C}$ in $5 \% \mathrm{CO}_{2}$ in air for $24 \mathrm{~h}$. Control embryos were not exposed to cryoprotectant, but were directly cultured in vitro. Survival of the embryos was assessed by their ability to subsequently develop into expanded or hatching blastocysts.

In Expt 1, embryos were exposed to increasing concentrations of cryoprotectants, $0,10,20,30$ or $40 \%(\mathrm{v} / \mathrm{v})$ in PBS plus CS for $10 \mathrm{~min}$ at room temperature. In Expt 2, embryos were exposed for 20 or $40 \mathrm{~min}$ to $20 \%$ (v/v) concentration of cryoprotectant in PBS plus CS at room temperature. In Expt 3, embryos were either directly diluted in PBS plus CS or $1 \mathrm{~mol}$ trehalose $\mathrm{1}^{-1}$ solution for $5 \mathrm{~min}$ after exposure to $(20 \% \mathrm{v} / \mathrm{v})$ concentration of cryoprotectant for $5 \mathrm{~min}$ at room temperature.

\section{Vitrification solutions}

On the basis of toxicity assays, three permeable cryoprotectants, ethylene glycol, dimethyl sulfoxide, and 1,3butanediol were selected as the components of a new vitrification solution. In this study, the equilibration solution (designated as ESv) consisted of 10\% ethylene glycol, 10\% dimethyl sulfoxide and 5\% 1,3-butanediol (v/v), and the vitrification solution (designated as VSv) consisted of $20 \%$ ethylene glycol, $20 \%$ dimethyl sulfoxide and $10 \%$ 1,3-butanediol ( $\mathrm{v} / \mathrm{v})$ in PBS plus CS.

\section{Confirmation of vitrification}

Vitrification of rapidly cooled VSv was confirmed by visual inspection of straws after cooling and during warming (Scheffen et al., 1986) and by freeze-fracture electron microscopy (Valdez et al., 1990a). In the first method, straws 
were filled with either ESv or VSv, heat sealed and then plunged directly into liquid nitrogen $\left(2500^{\circ} \mathrm{C} \min ^{-1}\right)$. The straws were then warmed by transfer into water at $20^{\circ} \mathrm{C}$. Straws were inspected for visible crystallization (whitening) after cooling and during warming.

Examination of vitrification solutions by freeze-fracture electron microscopy was as described by Valdez et al. (1990a). Twenty blastocysts were first equilibrated in ESv for $3 \mathrm{~min}$, and then exposed to VSv for $40 \mathrm{~s}$ at room temperature. A small drop $(1.5 \mu \mathrm{l})$ of VSv containing the embryos is pipetted on top of a small sample holder. It was then directly plunged into liquid nitrogen $\left(3000^{\circ} \mathrm{C} \mathrm{min}-1\right)$. Embryos that were cryo-fixed in isotonic PBS plus CS served as control. Each frozen specimen was transferred into a freeze-etching apparatus kept at a temperature of $-110^{\circ} \mathrm{C}$ in a vacuum of $1 \times 10^{-6}$ torr or lower. The specimen was fractured with a cold knife, etched for $1 \mathrm{~min}$ and replicated with platinum - carbon. After dissolving the specimen with a commercial bleach, the freeze-fracture replica was examined with a JEM $1200 \mathrm{EX}$ electron microscope at an accelerating voltage of $100 \mathrm{kV}$.

\section{Vitrification procedure}

The vitrification procedure was similar to that described by Scheffen et al. (1986) and Valdez et al. (1990b). Embryos were equilibrated by the two-step (ESv-VSv) or one-step (VSv) procedure at room temperature. In the twostep procedure, embryos were first equilibrated in ESv and then transferred to $20 \mu \mathrm{l}$ of VSv in a $0.25 \mathrm{ml}$ French straw (IMV, L'Aigle, France). The column of VSv in the straw was separated by two air bubbles from the 1 mol trehalose $1^{-1}$ solution placed on each side. In the one-step procedure, embryos were directly transferred to $20 \mu \mathrm{l}$ of VSv in the manner described above. The end of the straw was heat sealed, and the straw was then held vertically and plunged directly into liquid nitrogen. Vitrified embryos were stored for $1 \mathrm{~h}$ to 21 days in liquid nitrogen.

\section{Warming and cryoprotectant dilution}

The straws were warmed by gently shaking in a $20^{\circ} \mathrm{C}$ water bath until ice had disappeared from the trehalose solution (about $15 \mathrm{~s}$ ). The contents of each straw were then expelled into a sterilized plastic culture dish and held for 5 min at room temperature to dilute the cryoprotectant (Valdez et al., 1991). The embryos were then collected and washed three times in PBS plus CS. Embryo survival was assessed by in vitro culture as described above.

\section{In vitro experiments with or without vitrification}

In Expt 4, embryos were pipetted into plastic culture dishes containing $3 \mathrm{ml}$ of ESv or VSv and then exposed in the former for 3,20 or $60 \mathrm{~min}$ or in the latter for $0.5,1$ or $3 \mathrm{~min}$ at room temperature. After exposure, embryos were immediately diluted in 1 mol trehalose $\mathrm{I}^{-1}$, washed in PBS plus CS and then cultured in vitro. Nontreated control embryos were directly cultured in vitro.

In Expts 5 and 6, embryos were first equilibrated in ESv for $3 \mathrm{~min}$ before exposure to VSv for $0 \cdot 5,1,3$ or $5 \mathrm{~min}$ (Expt 5), or embryos were first equilibrated in ESv for 5,10 or $20 \mathrm{~min}$ before exposure to VSv for $0.5 \mathrm{~min}$ (Expt 6) at room temperature. In Expt 7, embryos were exposed directly to VSv for $0.5,1,3,5$ or $10 \mathrm{~min}$ at room temperature. Embryos were then vitrified by direct immersion into liquid nitrogen.

\section{In vivo development experiment}

In Expt 8, ten to fifteen embryos per straw were vitrified after two-step or one-step exposure. After warming and cryoprotectant dilution, the embryos were washed in PBS plus CS and maintained in this medium on a warm plate at $37^{\circ} \mathrm{C}$ until transfer.

All vitrified warmed embryos from the same straw, irrespective of their morphological appearance were transferred within $20 \mathrm{~min}$ after warming into the uterine horn of a day 4 pseudopregnant recipient that had been mated to a vasectomized male (day of vaginal plug = day 1 ). The day 4 recipients were in synchrony on the same day as the donors. The uterine transfer procedure was as described by Hogan et al. (1986) with modifications by Abas Mazni $e t$ al. (1990). Five to eight embryos were transferred into each uterine horn of recipients under anaesthesia. In the case of nonvitrified embryos (control), five to seven fresh embryos that were flushed on the same day as the vitrified embryos were transferred into each uterine horn.

All recipients were necropsied on day 17 of pregnancy, and the number of implantation sites, normal or abnormal fetuses were recorded.

\section{Statistical analysis}

Cryoprotectant toxicity data were analysed by two-way ANOVA to determine interactions among cryoprotectant type, concentration, duration of exposure and dilution. Duncan's multiple range test was used to determine differences between mean ( \pm SEM) viability rates. Survival rates of nonvitrified and vitrified warmed embryos in vitro and in vivo were analysed using the $\chi^{2}$ test. 


\section{Results}

\section{Effects of cryoprotectants on nonfrozen blastocysts}

Expt 1: Effect of cryoprotectant concentration. There was a significant interaction between concentration and cryoprotectant type as shown by two-way ANOva $(P<0.01)$ (Table 1$)$. At 10\% (v/v) concentration, high survival rates were obtained in all embryos exposed to cryoprotectants. At $20 \%(\mathrm{v} / \mathrm{v})$ concentration, survival rates significantly decreased $(P<0.05)$ for embryos exposed to 2,3-butanediol, propylene glycol and glycerol. At $30 \%$ concentration, embryos treated with ethylene glycol showed significantly higher survival rates $(P<0.05)$ than those exposed to the other cryoprotectants. At $40 \%$ concentration, very low or no survival was observed in all embryos exposed to the various cryoprotectants.

Table 1. Effect of cryoprotectant concentration on the development $( \pm \text { SEM })^{*}$ of nonfrozen mouse blastocysts in vitro after exposure for $10 \mathrm{~min}($ Expt 1)

\begin{tabular}{lcccc}
\hline & \multicolumn{4}{c}{ Cryoprotectant concentration $(\% \mathrm{v} / \mathrm{v})$} \\
Cryoprotectant & 10 & 20 & 30 & 40 \\
\hline 2,3-butanediol & $100 \cdot 0 \pm 0^{\mathrm{a}}$ & $66 \cdot 0 \pm 13 \cdot 6^{\text {bd }}$ & $8 \cdot 7 \pm 5 \cdot 3^{\text {cde }}$ & $0^{\text {cd }}$ \\
1,3-butanediol & $100 \cdot 0 \pm 0^{\mathrm{a}}$ & $96 \cdot 7 \pm 3 \cdot 3^{\text {ac }}$ & $1 \cdot 7 \pm 1 \cdot 7^{\text {bd }}$ & $0^{\text {bd }}$ \\
Dimethyl sulfoxide & $100 \cdot 0 \pm 0^{\mathrm{a}}$ & $98 \cdot 3 \pm 1 \cdot 7^{\text {ae }}$ & $25 \cdot 0 \pm 9 \cdot 6^{\text {be }}$ & $0^{\text {cd }}$ \\
Propylene glycol & $100 \cdot 0 \pm 0^{\text {a }}$ & $95 \cdot 0 \pm 1 \cdot 7^{\text {be }}$ & $2 \cdot 1 \pm 2 \cdot 1^{\text {cd }}$ & $0^{\text {cd }}$ \\
Ethylene glycol & $100 \cdot 0 \pm 0^{\text {a }}$ & $95 \cdot 9 \pm 2 \cdot 4^{\text {ae }}$ & $74 \cdot 6 \pm 2 \cdot 8^{\text {bf }}$ & $2 \cdot 1 \pm 2 \cdot 1^{\text {cd }}$ \\
Glycerol & $100 \cdot 0 \pm 0^{\text {a }}$ & $80 \cdot 9 \pm 8 \cdot 5^{\text {bde }}$ & $21 \cdot 9 \pm 6 \cdot 2^{\text {ce }}$ & $4 \cdot 2 \pm 5 \cdot 2^{\text {ce }}$ \\
Control & & & & \\
\hline
\end{tabular}

*Values were computed as number of embryos viable:number of embryos recovered (total of 44-60 embryos per treatment group; averaged over four replicates).

$\dagger$ Embryos not exposed to cryoprotectant had $100 \cdot 0 \pm 0$ survival rate after $24 \mathrm{~h}$ culture.

Values within rows with different superscripts $(\mathrm{a}, \mathrm{b}, \mathrm{c})$ are significantly different $(P<0.05)$.

Values within columns with different superscripts $(d, e, f)$ are significantly different $(P<0.05)$.

Expt 2: Effect of duration of exposure. There was no significant interaction between duration of exposure and cryoprotectant type as shown by two-way anova (Table 2). At 20 min exposure, 2,3butanediol showed significantly lower survival rate $(P<0.05)$ than those exposed to the other cryoprotectants. At 40 min exposure, both 2,3-butanediol and 1,3-butanediol showed significantly lower survival rates than those exposed to the other cryoprotectants $(P<0.05)$.

Table 2. Effect of duration of exposure on the development $( \pm$ SEM)* of nonfrozen mouse blastocysts in vitro exposed to $20 \%(\mathrm{v} / \mathrm{v})$ concentration of cryoprotectant (Expt 2)

\begin{tabular}{lcc}
\hline $\begin{array}{l}\text { Cryoprotectant } \\
(20 \% \mathrm{v} / \mathrm{v})\end{array}$ & \multicolumn{2}{c}{$\begin{array}{c}\text { Duration of exposure (min) } \\
20\end{array}$} \\
\hline 2,3-butanediol & $35 \cdot 9 \pm 21 \cdot 8^{\mathrm{a}}$ & $8 \cdot 3 \pm 5 \cdot 0^{\mathrm{a}}$ \\
1,3 -butanediol & $81 \cdot 2 \pm 9 \cdot 3^{\mathrm{b}}$ & $64 \cdot 2 \pm 12 \cdot 1^{\mathrm{b}}$ \\
Dimethyl sulfoxide & $93 \cdot 8 \pm 2 \cdot 2^{\mathrm{b}}$ & $96 \cdot 7 \pm 1 \cdot 9^{\mathrm{c}}$ \\
Propylene glycol & $91 \cdot 3 \pm 6 \cdot 3^{\mathrm{b}}$ & $87 \cdot 5 \pm 4 \cdot 4^{\mathrm{bc}}$ \\
Ethylene glycol & $96 \cdot 7 \pm 3 \cdot 3^{\mathrm{b}}$ & $95 \cdot 8 \pm 2 \cdot 5^{\mathrm{bc}}$ \\
Glycerol & $79 \cdot 2 \pm 8 \cdot 9^{\mathrm{bc}}$ & $81 \cdot 7 \pm 11 \cdot 4^{\mathrm{bc}}$
\end{tabular}

*Values were computed as number of embryos viable: number of embryos recovered (total of 50-55 embryos per treatment group; averaged over four replicates).

Values within columns with different superscripts $(a, b$, c) are significantly different $(P<0.05)$. 
Expt 3: Effect of cryoprotectant dilution. There was a significant interaction between dilution method and cryoprotectant type as shown by two-way ANova $(P<0.01)$ (Table 3$)$. It was observed that the survival of embryos exposed to glycerol and then directly diluted in PBS plus CS or $1 \mathrm{~mol}$ trehalose $1^{-1}$ was significantly different $(P<0.05)$. However, the survival of embryos exposed to the other cryoprotectants and then directly diluted in PBS plus CS or $1 \mathrm{~mol}$ trehalose $1^{-1}$ were not significantly different.

Table 3. Effect of method of dilution on the development $( \pm \mathrm{SEM})^{*}$ of nonfrozen mouse blastocysts in vitro exposed to $20 \%(\mathrm{v} / \mathrm{v})$ concentration of cryoprotectant for $5 \mathrm{~min}(\operatorname{Expt} 3)$

\begin{tabular}{lrr}
\hline \multirow{2}{*}{$\begin{array}{l}\text { Cryoprotectant } \\
(20 \% \mathrm{v} / \mathrm{v})\end{array}$} & \multicolumn{3}{c}{ Dilution method } \\
& PBS $+\mathrm{CS}$ & \multicolumn{1}{c}{ Trehalose } \\
\hline 2,3-Butanediol & $92 \cdot 5 \pm 4 \cdot 8^{\mathrm{c}}$ & $95 \cdot 0 \pm 2 \cdot 9$ \\
l,3-Butanediol & $98 \cdot 8 \pm 1 \cdot 2^{\mathrm{c}}$ & $100 \cdot 0 \pm 0 \cdot 0$ \\
Dimethyl sulfoxide & $98 \cdot 8 \pm 1 \cdot 2^{\mathrm{c}}$ & $100 \cdot 0 \pm 0 \cdot 0$ \\
Propylene glycol & $98 \cdot 8 \pm 1 \cdot 2^{\mathrm{c}}$ & $100 \cdot 0 \pm 0 \cdot 0$ \\
Ethylene glycol & $100 \cdot 0 \pm 0 \cdot 0^{\mathrm{c}}$ & $100 \cdot 0 \pm 0 \cdot 0$ \\
Glycerol & $28 \cdot 8 \pm 11 \cdot 3^{\text {ad }}$ & $96 \cdot 3 \pm 2 \cdot 4^{\mathrm{b}}$ \\
\hline
\end{tabular}

*Values were computed as number of embryos viable: number of embryos recovered (total of 59-60 embryos per treatment group; averaged over four replicates).

Values within rows with different superscripts $(a, b)$ are significantly different $(P<0.05)$.

Values within columns with different superscripts (c, d) are significantly different $(P<0.05)$.

PBS: phosphate-buffered saline; CS: calf-serum.

Confirmation of vitrification. Upon visual inspection of the straws after cooling and warming, ESv appeared milky and therefore, did not vitrify, whereas VSv appeared transparent, which indicated vitrification. A freeze replica image of a vitrified mouse blastocyst after exposure to ESv and VSv showed that there were no intracellular ice crystals in the cytoplasm. No extracellular ice crystals were observed (Fig. 1a). However, a freeze replica image of a mouse blastocyst cryofixed in PBS plus CS showed intracellular ice crystals in the cytoplasm (Fig. 1b).

\section{Development in vitro}

Expt 4: Effect of duration of exposure to ESv or VSv without vitrification. The in vitro survival rates of embryos exposed to ESv for 3 and $20 \mathrm{~min}$ at room temperature without vitrification were significantly higher than those exposed for $60 \mathrm{~min}(100.0$ and $97.7 \%$ versus $53.3 \%, P<0.001)$ (Table 4). However, the survival rates of embryos exposed to VSv for 0.5 and $1 \mathrm{~min}$ in vitro were significantly higher than those exposed for $3 \mathrm{~min}(100.0$ and $100.0 \%$ versus $0 \%, P<0.001)$. Nontreated control embryos showed a $100.0 \%$ survival rate in vitro.

Expts 5 and 6: Effect of duration of equilibration in ESv and VSv (two-step) followed by vitrification. In Expt 5 , the survival rates of vitrified warmed embryos that were exposed to VSv in vitro for 0.5 and 1 min after 3 min equilibration time in ESv at room temperature were significantly higher than those exposed to VSv for 3,5 and $10 \mathrm{~min}(96.2$ and $89.3 \%$ versus $25.9,9.5$ and $0 \%$ $(P<0.001)$ (Table 5).

In Expt 6, the in vitro survival rates of vitrified warmed embryos that were equilibrated in ESv for $5 \mathrm{~min}$ at room temperature before exposure to VSv for $0.5 \mathrm{~min}$ were significantly higher than those equilibrated in ESv for 10 and $20 \mathrm{~min}(91.3 \%$ versus 55.6 and $43.6 \%(P<0 \cdot 001)$ (Table 5). 

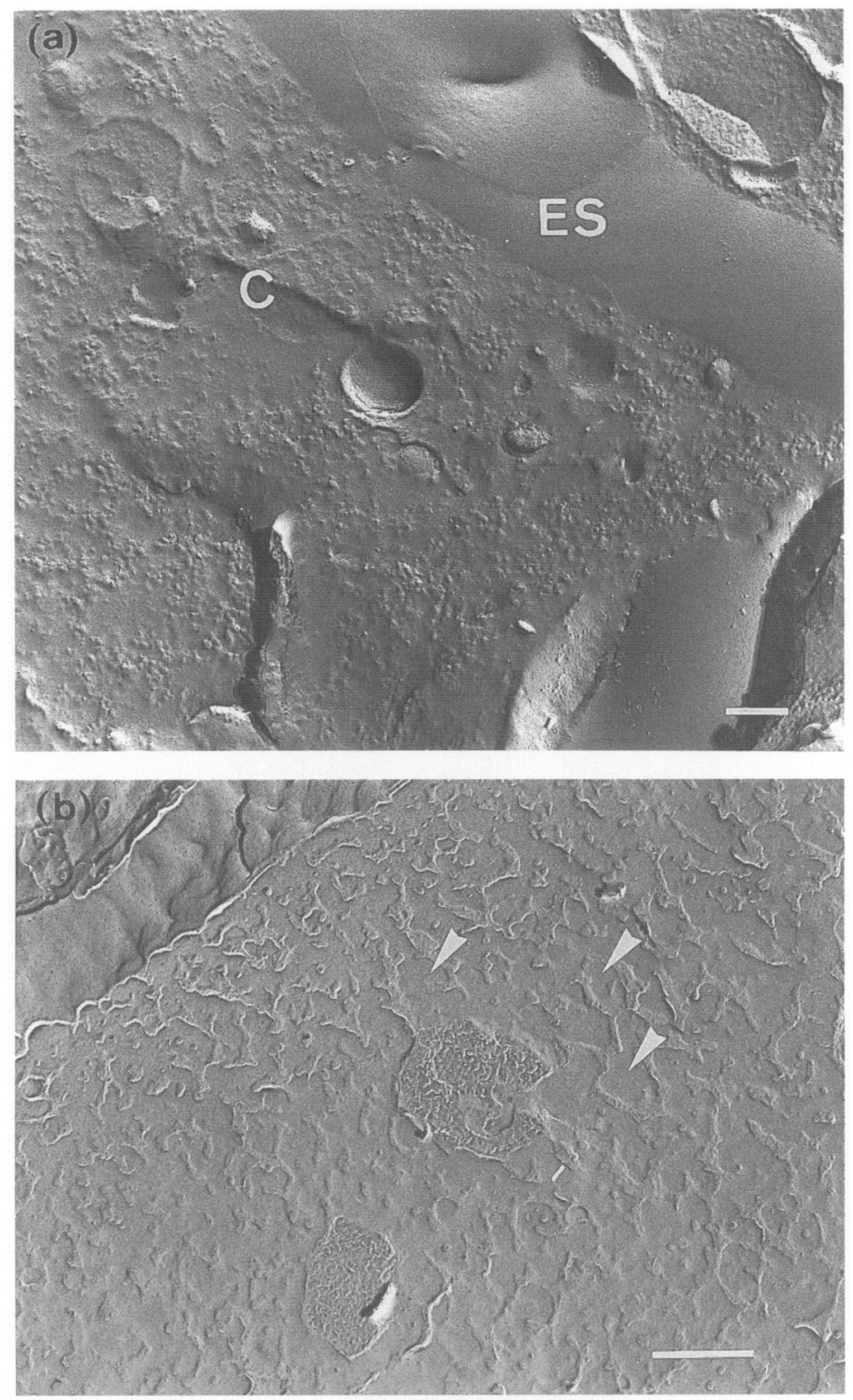

Fig. 1. (a) A freeze replica photograph of a vitrified mouse blastocyst. Note the absence of ice crystals in the cytoplasm (C) and extracellular solution (ES). Scale bar $=0 \cdot 2 \mu \mathrm{m}$. (b) A freeze replica photograph of a mouse blastocyst cryofixed in isotonic phosphate-buffered saline. Note the presence of ice erystals in the cytoplasm (arrows). Scale bar $=0.5 \mu \mathrm{m}$.

Expt 7: Effect of duration of exposure in VSv (one-step) followed by vitrification. The survival rates of vitrified warmed embryos exposed to VSv only for 0.5 and $1 \mathrm{~min}$ in vitro were significantly higher than those exposed to VSv for 3, 5, and $10 \mathrm{~min}(95.4$ and $94 \cdot 1 \%$ versus $29 \cdot 0,6 \cdot 7$ and $0 \%$, respectively, $P<0.001$ ) (Table 5).

Development in vivo. In Expt 8, a total of 16 out of 22 recjpients became pregnant after transfer of vitrified and nonvitrified embryos. Pregnancy rates of $66 \cdot 7(6 / 9), 80 \cdot 0(4 / 5)$, and $75 \cdot 0 \%(6 / 8)$ were obtained for two-step, one-step, and fresh (control) recipients, respectively (Table 6). The rates of implantation and development to normal fetuses of vitrified warmed embryos after two-step 
Table 4. Effect of duration of exposure to ESv or VSv on the development of mouse blastocysts in vitro without vitrification (Expt 4)

\begin{tabular}{lcc}
\hline $\begin{array}{l}\text { Exposure } \\
\text { time } \\
(\mathrm{min})\end{array}$ & $\begin{array}{c}\text { Number of } \\
\text { embryos* }\end{array}$ & $\begin{array}{c}\text { Development } \\
\text { after } 24 \mathrm{~h} \\
\text { in vitro }(\%)\end{array}$ \\
\hline $\mathrm{ESv}$ & & \\
3 & 45 & $45(100 \cdot 0)^{\mathbf{a}}$ \\
20 & 43 & $42(97 \cdot 7)^{\mathbf{a}}$ \\
60 & 45 & $24(53 \cdot 3)^{\mathrm{b}}$ \\
VSv & & \\
$0 \cdot 5$ & 38 & $38(100 \cdot 0)^{\mathbf{a}}$ \\
1 & 40 & $40(100 \cdot 0)^{\mathbf{a}}$ \\
3 & 45 & $0(0)^{\mathbf{b}}$ \\
Nontreated & & $45(100 \cdot 0)$ \\
Control & 45 & \\
\hline
\end{tabular}

*Total of three to four replicates per treatment group.

Values with different superscripts are significantly different $(P<0.001)$.

ESv: equilibration solution; VSv: vitrification solution.

Table 5. Effect of duration of equilibration in ESv and VSv (two-step) or VSv (one-step) on the development of vitrified warmed mouse blastocysts in vitro (Expts 5, 6 and 7)

\begin{tabular}{|c|c|c|c|c|}
\hline \multirow[b]{2}{*}{ Expt } & \multicolumn{2}{|c|}{$\begin{array}{l}\text { Equilibration } \\
\text { time (min) }\end{array}$} & \multirow{2}{*}{$\begin{array}{l}\text { Number of } \\
\text { embryos* }\end{array}$} & \multirow{2}{*}{$\begin{array}{c}\text { Development } \\
\text { after } 24 \mathrm{~h} \\
\text { in vitro }(\%)\end{array}$} \\
\hline & ESv & VSV & & \\
\hline \multirow[t]{5}{*}{ Expt 5} & 3 & 0.5 & 104 & $100(96 \cdot 2)^{a}$ \\
\hline & 3 & 1 & 56 & $50(89 \cdot 3)^{\mathrm{a}}$ \\
\hline & 3 & 3 & 54 & $14(25.9)^{\mathrm{b}}$ \\
\hline & 3 & 5 & 42 & $4(9 \cdot 5)^{c}$ \\
\hline & 3 & 10 & 30 & $0(0 \cdot 0)^{\mathrm{c}}$ \\
\hline \multirow[t]{3}{*}{ Expt 6} & 5 & $0 \cdot 5$ & 92 & $84(91 \cdot 3)^{\mathrm{a}}$ \\
\hline & 10 & 0.5 & 90 & $50(55 \cdot 6)^{\mathrm{b}}$ \\
\hline & 20 & $0 \cdot 5$ & 39 & $17(43 \cdot 6)^{b}$ \\
\hline \multirow[t]{5}{*}{ Expt 7} & 0 & 0.5 & 65 & $62(95.4)^{\mathrm{a}}$ \\
\hline & 0 & 1 & 51 & $48(94 \cdot 1)^{\mathrm{a}}$ \\
\hline & 0 & 3 & 69 & $20(29 \cdot 0)^{b}$ \\
\hline & 0 & 5 & 30 & $2(6.7)^{\mathrm{c}}$ \\
\hline & 0 & 10 & 32 & $0(0.0)^{\mathrm{cd}}$ \\
\hline
\end{tabular}

*Total of three to eight replicates per treatment group. Values with different superscripts are significantly different (a, b; a, c; b, d: $P<0.001)(b, c: P<0.05)$.

ESv: equilibration solution; VSv: vitrification solution.

exposure (65.3 and $54.2 \%$, respectively) did not significantly differ from that of the nonvitrified control group ( 78.6 and $60.0 \%$, respectively). Although a significant difference $(P<0.05)$ was observed between the rate of implantation of vitrified warmed embryos after one-step exposure $(60.0 \%)$ and that of the control $(78.6 \%)$, no significant difference $(P>0.05)$ was observed in the rate of development to normal fetuses $(60 \cdot 0$ versus $45 \cdot 0 \%)$. 
Table 6. In vivo development of vitrified warmed mouse blastocysts transferred to pseudopregnant recipients* (Expt 8)

\begin{tabular}{lcccc}
\hline $\begin{array}{l}\text { Treatment } \\
\text { group }\end{array}$ & $\begin{array}{c}\text { Pregnant } \\
\text { recipients }\end{array}$ & $\begin{array}{c}\text { Number of } \\
\text { embryos } \\
\text { transferred }\end{array}$ & $\begin{array}{c}\text { Number of } \\
\text { implantations } \\
(\%) \dagger\end{array}$ & $\begin{array}{c}\text { Number of } \\
\text { normal fetuses } \\
(\%) \ddagger\end{array}$ \\
\hline $\begin{array}{l}\text { Vitrified } \\
\text { two-step } \\
\text { one-step }\end{array}$ & 6 & 72 & $47(65 \cdot 3)^{\mathbf{a b}}$ & $39(54 \cdot 2)$ \\
$\begin{array}{l}\text { Nonvitrified fresh } \\
\text { (control) }\end{array}$ & 4 & 40 & $24(60 \cdot 0)^{\mathrm{a}}$ & $18(45 \cdot 0)$ \\
\hline
\end{tabular}

* Necropsied at day 17 of pregnancy.

$\dagger$ Represents normal, premature or resorbing fetuses and implantation sites.

$\$$ Number of normal fetuses: number of embryos transferred.

Values with different superscripts in each column are significantly different $(\mathrm{a}, \mathrm{b} ; P<0.05)$.

\section{Discussion}

This study shows that a combination of three permeating cryoprotectants, ethylene glycol, dimethyl sulfoxide and 1,3-butanediol is effective for the cryopreservation of mouse blastocysts by vitrification.

In the process of composing a new vitrification solution, toxicity assays were first conducted to determine the least harmful cryoprotectants that could be used. Results showed that cryoprotectants can induce injury to nonfrozen mouse blastocysts to varying degrees at room temperature depending on the type of cryoprotectant used. A two-way interaction between cryoprotectant type, concentration and method of dilution had a significant effect on subsequent embryo survival in vitro $(P<0.01)$. Ethylene glycol seemed the least harmful of the six cryoprotectants examined for mouse blastocysts. This result is consistent with previous reports (Kasai et al., 1981; Kasai et al., 1990) that ethylene glycol is less toxic to nonfrozen mouse morulae at room temperature than other cryoprotectants. Hence, ethylene glycol was selected as the first component of the solution under study. In addition, ethylene glycol was reported to provide considerable protection against freezing damage to mouse and rat embryos (Miyamoto \& Ishibashi, 1978) and has been successfully used for the quick freezing (Abas Mazni et al., 1990) and vitrification (Kasai et al., 1990) of mouse morulae and Drosophila embryos (Steponkus et al., 1990). Ethylene glycol has also been shown to protect rye protoplasts from dehydration injury during vitrification (Langis \& Steponkus, 1991) and may have a similar effect on mouse embryos. However, ethylene glycol has been reported to be a weak glass former compared with dimethyl sulfoxide and 1,3-butanediol (Fahy et al., 1987). Since vitrification relies on a sufficiently concentrated solution that solidifies as glass during cooling without appreciable ice formation, dimethyl sulfoxide and 1,3-butanediol were included as additional components of the new vitrification solution to take advantage of their strong glass forming abilities to achieve vitrification at a low concentration of cryoprotectants thus minimizing chemical toxicity (MacFarlane \& Forsyth, 1990). Moreover, dimethyl sulfoxide has been reported to be efficient for ultrarapid freezing of mouse embryos (Trounson et al., 1987; Shaw \& Trounson, 1989), and is one of the main components of the first vitrification solution for mouse embryos (VS1; Rall \& Fahy, 1985). On the other hand, 1,3-butanediol has been used successfully for the cryopreservation of human red blood cells (Mehl \& Boutron, 1988), but to our knowledge this is the first time it was used for the cryopreservation of mouse embryos.

Our results confirm earlier reports (Rall \& Fahy, 1985; Scheffen et al., 1986; Valdez et al., $1990 \mathrm{~b})$ that exposure to vitrification solutions produces time-dependent injury, i.e. prolonged exposure was detrimental to subsequent embryo survival.

Prolonged exposure of embryos to ESv or VSv at room temperature without vitrification results in reduced survival rates in vitro. However, VSv is more detrimental to embryo survival than ESv. 
On the basis of these results, we adopted a two-step exposure period before vitrification by rapid cooling to $-196^{\circ} \mathrm{C}$. In addition, it has been suggested that the use of a stepwise equilibration procedure controls the extent of cryoprotectant permeation, and thus prevents injury due to chemical toxicity or excessive osmotic stresses during equilibration or subsequent dilution (Rall, 1987).

Our results show high survival rates of vitrified warmed embryos in vitro after two-step exposure when the embryos are first equilibrated in ESv for 3 to $5 \mathrm{~min}$ before exposure to VSv for $0.5 \mathrm{~min}$. When the embryos are equilibrated in ESv for $3 \mathrm{~min}$ and exposed to VSv for increasing periods, a high survival rate is observed in vitro only up to 1 min exposure in VSv, but sharply decreased after $3 \mathrm{~min}$. These results suggest that prolonged exposure in both ESv and VSv is detrimental to subsequent embryo survival of vitrified warmed embryos. However, the exposure time in the latter is more critical than in the former.

Our results further show that it is possible to achieve high survival rates in vitro after one-step exposure to VSv even without full equilibration in ESv provided the embryos are exposed for only a short period, i.e. 0.5 or $1 \mathrm{~min}$. Prolonged exposure to VSv for 3,5 or $10 \mathrm{~min}$ appeared very damaging to the embryos as shown by the very low survival rates. However, it is difficult to explain why some vitrified warmed embryos exposed to VSv for $3 \mathrm{~min}$ survived, whereas none of the embryos exposed under similar condition without vitrification survived (Expt 4). This is probably related to differences in the method of dilution or volume of diluent during dilution between vitrified and nonvitrified exposed embryos.

Results of the exposure experiments agree with the previous conclusions that some permeation is necessary for successful cryopreservation by vitrification, but complete permeation is not desirable because it increases the likelihood of injury due to chemical toxicity or excessive osmotic swelling during dilution (Rall, 1987).

The in vitro results obtained in this study either by two-step $(96 \cdot 2 \%)$ or one-step $(95.4 \%)$ exposure to the vitrification solution at room temperature were higher than those reported for mouse blastocysts in previous studies (Scheffen et al., 1986; Bielanski, 1987; Valdez et al., 1990b) using the vitrification solution developed by Scheffen et al. (1986). Our results were also higher than those reported for rat blastocysts by Kono et al. (1988) using the solution (VS1) developed by Rall \& Fahy (1985).

Our results also demonstrate that normal fetuses could be obtained from vitrified warmed blastocysts that are transferred immediately after warming to pseudopregnant recipients. This observation indicates that it is not necessary to culture the embryos in vitro to obtain high in vivo development. Moreover, our results represent a conservative estimate of survival in vivo since all vitrified embryos recovered after warming, regardless of their morphology, were transferred to recipients. Although a higher rate of development to normal fetuses was obtained for embryos vitrified after two-step compared with one-step exposure ( 54.2 versus $45.0 \%$ ), no significant difference was observed. Our development results from experiments in vivo are higher than those of Kono et al. (1988) for vitrified warmed rat blastocysts (41\%), and those of Scheffen et al. (1986) and Rall et al. (1987) for vitrified warmed day $4(30 \%)$ and day $3(17 \%)$ mouse embryos, respectively. Kasai et al. (1990) and Valdez et al. (1990c) reported similar results after transfer of vitrified warmed mouse morulae (51 and $53.6 \%$, respectively). Our results, however, are lower than those obtained after transfer of frozen-thawed mouse blastocysts cryopreserved by a simplified freezing method $(60 \cdot 3 \%$; Landa, 1982) or by conventional freezing $(63 \cdot 2 \%$; Whittingham et al., 1979).

The vitrification solution developed in this study is simple and does not require precooling to achieve high survival rate. It can be used effectively for the cryopreservation of mouse blastocysts by vitrification. However, the ultrastructural changes that occur when embryos are exposed to vitrification solutions need to be investigated so that more effective and reliable vitrification solutions that are suitable for each embryo developmental stage or species can be developed. 
This work was supported by Grants-in-Aid for Scientific Research (No. 2556039) from the Ministry of Education, Science and Culture, Japan and special Grants-in-Aid for the Promotion of Education and Science at Hokkaido University.

\section{References}

Abas Mazni, O., Valdez, C.A., Takahashi, Y., Hishinuma, M. \& Kanagawa, H. (1990) Quick freezing of mouse embryos using ethylene glycol with lactose or sucrose. Animal Reproduction Science 22, 161-169.

Bielanski, A. (1987) Survival in vitro of zona pellucidafree mouse embryos after cooling by conventional two-step or vitrification methods. Cryo-Letters 8 , 294-301.

Biggers, J.D., Whitten, W.K. \& Whittingham, D.G. (1971) The culture of mouse embryos in vitro. In Methods in Mammalian Embryology, pp. 110-112. Ed. J. C. Daniels Jr. W. H. Freeman and Co., San Francisco.

Fahy, G.M., Levy, D.I. \& Ali, S.E. (1987) Some emerging principles underlying the physical properties, biological actions, and utility of vitrification solutions. Cryobiology 24, 196-231.

Hogan, B., Constantini, F. \& Lacy, E. (1986) Recovery, culture and transfer of embryos. In Manipulating the Mouse Embryo, pp. 142-145. Cold Spring Harbor, NY.

Kasai, M., Niwa, K. \& Iritani, A. (1981) Effects of various cryoprotective agents on the survival of unfrozen and frozen mouse embryos. Journal of Reproduction and Fertility 63, 175-180.

Kasai, M., Komi, J.H., Takakamo, A., Tsudera, H., Sakurai, T. \& Machida, T. (1990) A simple method for mouse embryo cryopreservation in a low toxicity vitrification solution, without appreciable loss of viability. Journal of Reproduction and Fertility $\mathbf{8 9}$, 91-97.

Kono, T., Suzuki, O. \& Tsunoda, Y. (1988) Cryopreservation of rat blastocysts by vitrification. Cryobiology $25,170-173$.

Landa, V. (1982) A simplified method for freezing mouse blastocysts. Folia Biologica (Praha) 28, 266- 273.

Langis, R. \& Steponkus, P.L. (1991) Vitrification of isolated rye protoplasts: protection against dehydration injury by ethylene glycol. Cryo-Letters $12,107-112$.

MacFarlane, D.R. \& Forsyth, M. (1990) Recent insights on the role of cryoprotective agents in vitrification. Cryobiology 27, 345-358.

Mazur, P. (1984) Freezing of living cells: mechanism and implications. American Journal of Physiology 247 (Cell Physiology 16:C125-C142).

Mehl, P. \& Boutron, P. (1988) Cryoprotection of red blood cells by 1,3 butanediol and 2,3 butanediol. Cryobiology 25, 44-54.

Miyamoto, H. \& Ishibashi, T. (1978) The protective action of glycols against freezing damage of mouse and rat embryos. Journal of Reproduction and Fertility 54, 427-432.
Rall, W.F. (1987) Factors affecting the survival of mouse embryos cryopreserved by vitrification. Cryobiology 24, 387-402.

Rall, W.F. \& Fahy, G.M. (1985) Ice-free cryopreservation of mouse embryos at $-196^{\circ} \mathrm{C}$ by vitrification. Nature 313, 573-575.

Rall, W.F., Wood, M.J., Kirby, C. \& Whittingham, D.G. (1987) Development of mouse embryos cryopreserved by vitrification. Journal of Reproduction and Fertility 80, 499-504.

Scheffen, B., Van Der Zwalmen, P. \& Massip, A. (1986) A simple and efficient procedure for preservation of mouse embryos by vitrification. Cryo-Letters 7, $260-269$.

Shaw, J.M. \& Trounson, A.O. (1989) Effect of dimethyl sulfoxide and protein concentration on the viability of two-cell mouse embryos frozen with a rapid freezing technique. Cryobiology 26, 413-421.

Steponkus, P.L., Myers, S.P., Lynch, D.V., Gardner, V., Bronhteyn, V., Leibo, S.P., Rall, W.F., Pitt, R.E., Lin, T.T. \& Macintyre, R.J. (1990) Cryopreservation of Drosophila melanogaster embryos. Nature 345, 170-172.

Trounson, A., Peura, A. \& Kirby, C. (1987) Ultrarapid freezing: a new low-cost and effective method of embryo cryopreservation. Fertility and Sterility 49, 843-850.

Valdez, C.A., Abas Mazni, O., Kanagawa, H. \& Fujikawa, S. (1990a) Confirmation by cryo-electron microscopy of the absence of crystallization using a vitrification solution. Cryo-Letters 11, 351-358.

Valdez, C.A., Abas Mazni, O., Takahashi, Y., Hishinuma, M. \& Kanagawa, H. (1990b) Effects of equilibration time, precooling and developmental stage on the survival of mouse embryos cryopreserved by vitrification. Theriogenology 33, 627-636.

Valdez, C.A., Abas Mazni, O., Taniguchi, T., Hishinuma, M. \& Kanagawa, H. (1990c) In vitro and in vivo development of vitrified-thawed mouse morulae. Proceedings 7th Congress of the Federation of Asian Veterinary Association, pp. 844-850. Eds P. Poomvises \& P. Ingkaninum. Chulalongkorn University Press, Bangkok, Thailand.

Valdez, C.A., Hishinuma, M., Takahashi, Y. \& Kanagawa, H. (1991) Effect of trehalose dilution on the survival of vitrified-thawed mouse morulae. Japanese Journal of Veterinary Research 39, 23-26.

Whittingham, D.G., Woods, M.J., Farrant, J., Lee, H. \& Halsey, J.A. (1979) Survival of frozen mouse embryos after rapid thawing from $-196^{\circ} \mathrm{C}$. Journal of Reproduction and Fertility 56, 11-21.

Received 25 November 1991 